University of Nebraska - Lincoln

DigitalCommons@University of Nebraska - Lincoln

Faculty Publications from the Harold W. Manter Laboratory of Parasitology

2-1957

\title{
Studies on the Helminth Fauna of Alaska. XXXI. Observations on the Propagation of the Larval Echinococcus multilocularis Leuckart, 1863, In Vitro
}

Robert L. Rausch

Arctic Health Research Center, rausch@u.washington.edu

Virginia Jentoft

Arctic Health Research Center

Follow this and additional works at: https://digitalcommons.unl.edu/parasitologyfacpubs

Part of the Parasitology Commons

Rausch, Robert L. and Jentoft, Virginia, "Studies on the Helminth Fauna of Alaska. XXXI. Observations on the Propagation of the Larval Echinococcus multilocularis Leuckart, 1863, In Vitro" (1957). Faculty Publications from the Harold W. Manter Laboratory of Parasitology. 586.

https://digitalcommons.unl.edu/parasitologyfacpubs/586

This Article is brought to you for free and open access by the Parasitology, Harold W. Manter Laboratory of at DigitalCommons@University of Nebraska - Lincoln. It has been accepted for inclusion in Faculty Publications from the Harold W. Manter Laboratory of Parasitology by an authorized administrator of DigitalCommons@University of Nebraska - Lincoln. 


\section{The Journal of Parasitology}

Volume 43

FEBRUARY, 1957

Number 1

STUDIES ON THE HELMINTH FAUNA OF ALASKA. XXXI.

OBSERVATIONS ON THE PROPAGATION OF THE

LARVAL ECHINOCOCCUS MULTILOCULARIS

LEUCKART, 1863, IN VITRO

Robert Rausch and Virginia L. Jentoft

Arctic Health Research Center, Public Health Service,

U. S. Department of Health, Education, and Welfare, Anchorage, Alaska

Larval reproduction in Echinococcus multilocularis Leuckart, 1863, takes place through the proliferation of exogenous secondary vesicles (Rausch, 1954). In some species of host this process appears to be continual, extending over a long period of time with little tendency for self-limitation. Consequently, the growth characteristics of this larval cestode are such that it would seem well suited to culture in vitro.

Beginning in November, 1955, the writers have attempted to propagate the larval E. multilocularis in tissue culture. This paper constitutes a preliminary report of the results of this work.

\section{METHODS}

Each of 4 experiments consisted of the inoculation of a series of culture tubes. The culture medium consisted essentially of $40 \%$ human ascitic fluid in Hank's basic salt solution. To this was added 100 units of penicillin and $100 \mu \mathrm{gm}$ of streptomycin per $\mathrm{ml}$. Phenol red is the indicator in Hank's solution. Some tubes were also inoculated with a malignant human epithelial cell (HeLa strain), which was allowed to become well established before the cestode tissue was introduced. In some cases, extract of vole embryo (Microtus) or human plasma was added.

Screw-cap tubes were used routinely, but Leighton tubes were also used in an attempt to follow better the development of individual vesicles. In an effort to immobilize groups of vesicles, perforated cellophane was placed in some of the tubes. The tubes were incubated at $35^{\circ} \mathrm{C}$ in a horizontal position without rotation.

Tissue of larval cestodes was collected aseptically from the livers of experimentally infected rodents. Three species of hosts were utilized: field vole, Microtus pennsylvanicus Ord; red-backed vole, Clethrionomys rutilis Pallas; brown lemming, Lemmus sibiricus Kerr. ${ }^{1}$ After removal from the host, the larval tissue (in some cases with small quantities of hepatic cells) was finely divided with scissors. The resulting material was introduced by pipette into the culture tubes.

The medium was changed on an average of every 3 to 4 days, or whenever this was indicated by a drop in $\mathrm{pH}$. In some instances, the $\mathrm{pH}$ was temporarily adjusted by the addition of isotonic sodium bicarbonate, or by the addition of $5 \%$ $\mathrm{CO}_{2}$ in air.

Received for publication June 7, 1956. reared.

1 The experimental animals, with the exception of the red-backed voles, were laboratory- 
From time to time, masses of larval vesicles were removed from the culture tubes for study. These were either stained with Semichon's acetic carmine and prepared as whole mounts, or were embedded by the paraffin method and sectioned. Sections were stained with hematoxylin-eosin.

In order to determine whether the larvae developed normally in vitro, fragments of tissue or small vesicles were removed from time to time and injected intraperitoneally into susceptible hosts. Such material was later recovered from the host for study.

\section{RESULTS}

Since the procedures followed differed for each, the 4 experiments are described separately.

Experiment I. Infective larvae of E. multilocularis were removed from the liver of a brown lemming, infected 171 days before. Five tubes were inoculated; 4 contained well established HeLa cells, and one contained only the basic medium. Intact scolices, freed from the enclosing vesicles, showed motility for a period of about 7 days. After this period, some showed evidence of degeneration; others, however, retained a normal appearance up to 60 days. Areas of hyaline tissue were noted on the 28th day in one of the tubes containing HeLa cells, and this was tentatively identified as larval tissue. Similar growth was noted on the walls of the other tubes during the next few days. By the 35th day, the HeLa cells appeared to be degenerating. No formation of vesicles was observed, and the experiment was discontinued on the 67 th day.

Experiment II. The larval tissue was obtained from the liver of a red-backed vole infected 46 days previously; this material contained well developed scolices. Fifteen tubes were inoculated: 7 contained HeLa cells and vole embryo extract; 4 contained embryo extract without HeLa cells; 4 contained basic medium. Two tubes with HeLa cells were kept as controls.

On the 7 th day after inoculation of the tubes, small areas of hyaline tissue were noted on the sides of a tube containing both HeLa cells and embryo extract. Some of this material, along with many HeLa cells, was scraped off the surface of the glass and withdrawn suspended in about $2 \mathrm{ml}$ of medium. One $\mathrm{ml}$ of this suspension was injected intraperitoneally into 2 voles. One animal died early and was not examined. The second animal, when autopsied 45 days later, contained many free vesicles in the body cavity, and a mass of vesicles was attached to the abdominal wall at the site of injection.

Between the 10th and 16th days, hyaline growth was noted in the remainder of the inoculated tubes. This tissue was usually seen as minute plaques with clear centers. Proliferation of this tissue continued between the 16th and 26th days. On the 22nd day, vesicles were recognized in tubes containing $\mathrm{HeLa}$ cells and embryo extract; these were embedded in the layer of HeLa cells on the surface of the tubes. On the 29th day, the proliferation of larval vesicles was well advanced, with the best growth in those tubes having HeLa cells and embryo extract.

On the 30th day, some of the larger vesicles contained in their walls bodies identified as calcareous corpuscles (Fig. 1). The vesicles in the culture tubes were identical in structure and appearance with those seen at a similar stage of development in vivo. Transverse strands of tissue extended across the lumen of larger vesicles, possibly representing an early stage in the development of septa. Larval 
vesicles were removed from a tube containing HeLa cells and embryo extract, and injected intraperitoneally into a vole. When the vole was killed 22 days later, 2 small vesicles, containing scolices, were found free in the body cavity. These closely resembled those seen in the tissue cultures on the 52nd day.

By the 34th day, the groups of vesicles were easily seen macroscopically. Single vesicles ranged up to 640 microns in diameter. Calcareous corpuscles and transverse strands of tissue were present in the larger vesicles. Vesicles were detached from the walls of 2 tubes which contained HeLa cells and embryo extract. From the first tube, a small quantity of tissue was fixed in $10 \%$ formalin. This tissue was divided; one half was prepared as a whole mount, and the other was sectioned. The study of this material disclosed numerous vesicles, ranging in size up to $1 \mathrm{~mm}$,

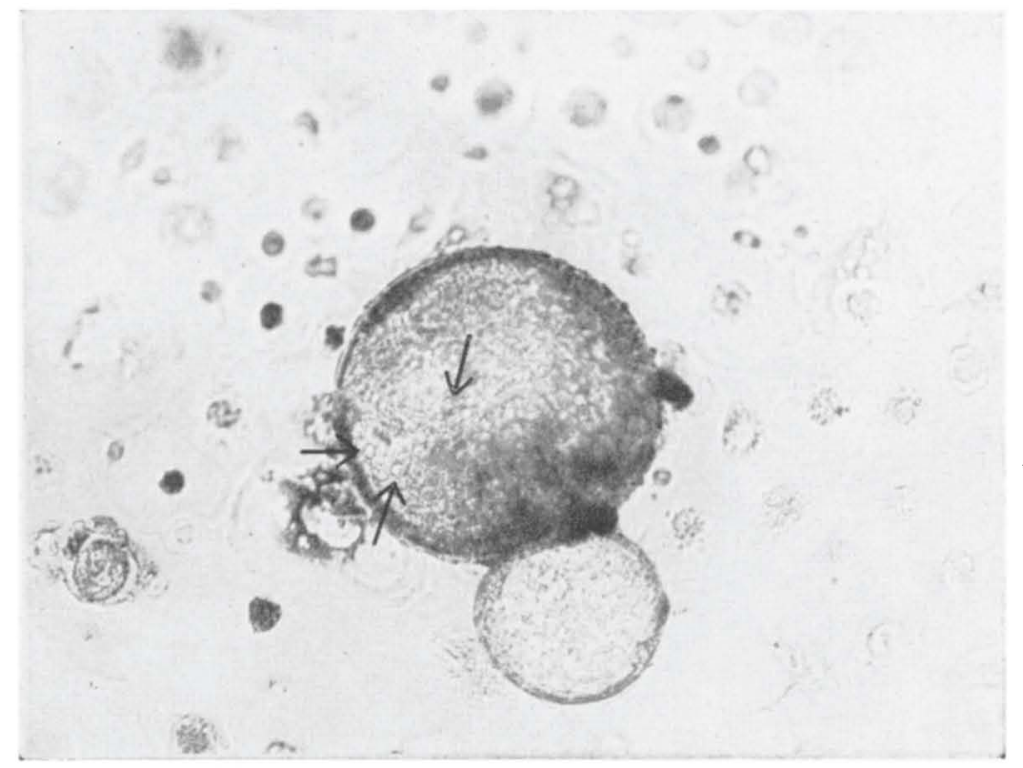

Figure 1. Early vesicles of E. multilocularis in tissue culture. The larger vesicle, measuring 360 microns in diameter, shows calcareous corpuscles, indicated by arrows.

embedded in a thick matrix of HeLa cells. The sub-germinal membrane was present, and measured about 5 microns in thickness. The germinal membrane was well developed and cellular. An immature but well developed scolex was observed in one of the sectioned vesicles.

From the first tube, above, tissue was injected intraperitoneally into 2 lemmings. One animal died within a few days, and was not examined. The second animal was examined 61 days later, and an abscess $15 \mathrm{~mm}$ in diameter was found at the site of injection. No evidence of larvae was noted. Two lemmings were also injected with material from the second tube, and examined 61 days later. In each a mass of vesicles was found in the subcutaneous tissue at the site of injection. Individual vesicles ranged in size up to $4 \mathrm{~mm}$, and contained fully developed scolices.

By the 42nd day, masses of HeLa cells had surrounded the aggregations of vesicles, and the best growth of the larvae was seen in those tubes containing the cells and embryo extract. By this time masses of vesicles, with their surrounding 
cells, had fallen away from the walls of the tubes and were free in the medium. Numerous separate vesicles were seen, these having become detached from the masses from which they had originated. Scolices were readily visible in larger vesicles.

Two lemmings were injected on the 48th day, and 2 red-backed voles were injected on the 52nd day. All were negative when examined from 44 to 47 days later.

On the 55th day, 2 vesicles contained 20 and 12 scolices, respectively. From the 56th to the 70th day, there was some degeneration of the HeLa cells, and this resulted in the freeing of more vesicles. In some tubes, the larvae had been completely overgrown by the cells, and appeared to be degenerating. On the 73rd day, it was noted that some vesicles had ruptured, and the scolices had fallen free in the medium. From the 73 rd to the 120 th days, the best vesicles were seen in the

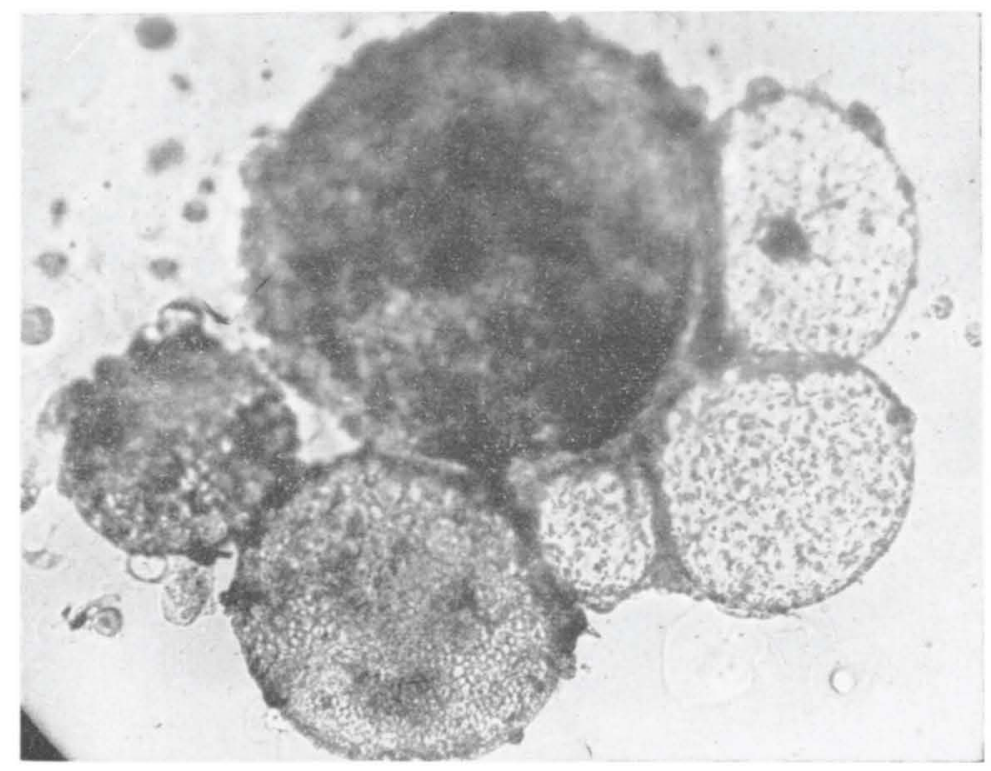

Figure 2. A group of vesicles of E. multilocularis produced in vitro, attached to the surface of the tube. The largest vesicle, measuring 500 microns in diameter, gave rise to the smaller vesicles, the most recent of which are characterized by very thin walls.

tubes containing only the basic medium. In some of the tubes containing HeLa cells, new areas of growth of the hyaline tissue were observed. The experiment was terminated on the 134th day.

Experiment III. Larvae were taken from the liver of a red-backed vole on the 10th day following infection. Forty tubes were inoculated, as follows: 13 Leighton tubes containing HeLa cells; 7 Leighton tubes containing HeLa cells and human plasma; 3 Leighton tubes and 3 screw-cap tubes containing basic medium with perforated cellophane; 3 Leighton tubes and 3 others containing basic medium and human plasma, with perforated cellophane; 8 tubes containing only basic medium. Four tubes containing HeLa cells were kept as controls.

Since many of the larval vesicles removed from the vole were very small, some were not ruptured when the tissue was divided with scissors. Such intact vesicles 
were relatively thick-walled and were surrounded in part by hepatic cells. The proliferation of new vesicles was rapid, but these were readily distinguished from the original vesicles by their thin, fragile walls (Figs. 2 and 3 ).

On the third day, new vesicles ranging in diameter from 50 to 130 microns were observed, budding from the original vesicles. The latter were thin-walled and very fragile, sometimes rupturing when the medium was slightly agitated by rotation of the tube. Proliferation of new vesicles proceeded at about the same rate in all media. By the 12th day, vesicles measured up to 290 microns in diameter. Between the 17 th and 24 th day, many masses of vesicles no longer adhered to the walls of the tubes, making impossible continued observation of marked areas. Many of the tubes were discarded on the 19th day. On the 25th day, 8 single vesicles ranging in diameter from 500 to 1100 microns were isolated in tubes of basic medium. Seven days later these had grown very little, with a maximum increase in diameter of about 100 microns. Hepatic cells, introduced

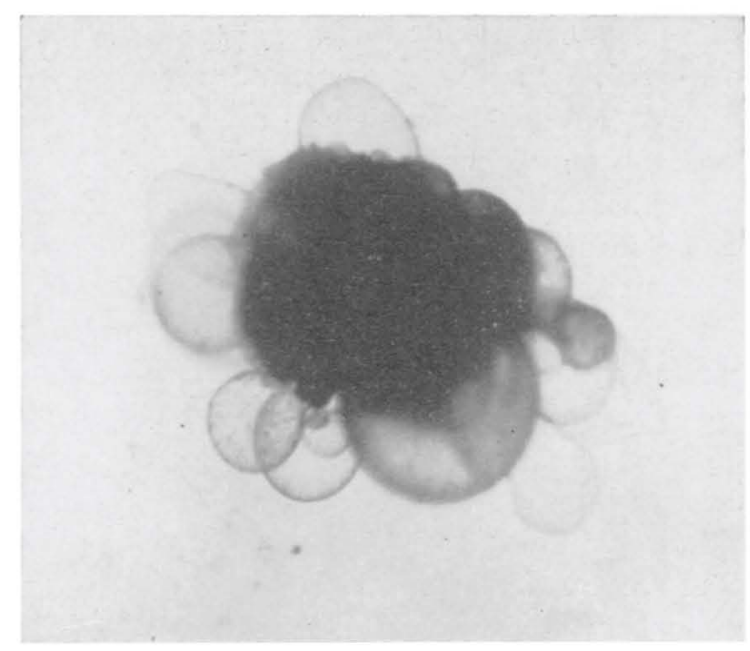

Figure 3. New vesicles of E. multilocularis arising from a vesicle inoculated intact. The latter is surrounded by host tissue. Total length of mass, $3 \mathrm{~mm}$.

at the time of inoculation, were found among the Hela cells and persisted over 40 days. Proliferation of vesicles continued in the remaining tubes up to 40 days, but those in tubes containing HeLa cells were gradually surrounded and overgrown. Some tubes were observed as long as 63 days, after which the experiment was discontinued.

Experiment IV. Larval tissue was removed from the liver of a red-backed vole 37 days after infection. The tissue was washed in Hank's solution, transferred to a sterile Petri dish, and finely divided with scissors. Part of this tissue was added to a few $\mathrm{ml}$ of Hank's solution and filtered through sterile gauze. The filtrate was placed in the following tubes: 8 containing HeLa cells; 5 containing basic medium; 8 containing basic salt solution plus fresh ascitic fluid from a patient with carcinoma. Unfiltered tissue was placed in 6 tubes of basic medium, of which 3 contained perforated cellophane. On the 4th day, a heavy suspension of HeLa cells was added to half of all tubes not already containing them. 
On the 7th day, vesicles from 180 to 400 microns in diameter were present in the tubes receiving the filtrate. Later growth of vesicles was poor, and observations were discontinued on the 24 th day.

\section{DISCUSSION}

Previous attempts to culture larval cestodes of the genus Echinococcus have involved E. granulosus (Batsch, 1786). In the year 1900, Dévé (1926) tried unsuccessfully to maintain larval vesicles in vitro. Vesicles of human origin were placed in tubes containing human ascitic fluid; however, they had degenerated when examined 28 days later, apparently as a result of bacterial contamination. Dévé (1926) later was able to keep larval scolices in vitro for a period of 14 days, during which time some became vesicular. For this work, the contents of several vesicles of ovine origin were collected in sterile tubes. Into each tube was introduced $2 \mathrm{ml}$ of clear hydatid fluid, and to this was added 0.5 to $1 \mathrm{ml}$ of recently collected, unheated equine serum. The tubes were covered and incubated at $37^{\circ} \mathrm{C}$. Samples of scolices were removed daily for examination. After the 4th day, some of the scolices had become "hydropic" and were becoming vesicular. By the 14th day, some of the scolices had doubled or tripled in size and were clearly vesicular. Dévé regarded these as being viable and in good condition.

Studies similar to those of Dévé were continued by Coutelen (1927a) who attempted to define some of the physical requirements in vitro of the larval $E$. granulosus. The larval cestodes were collected aseptically from the hosts, and placed in sterile containers. Various bacteriological media were tried, with negative results, but evagination of the scolices took place in sterile, unfiltered hydatid fluid. Some of these were becoming vesicular, but they did not survive long. Various media containing hydatid fluid and extracts of organs gave promising results, and scolices from the liver of a pig were maintained for 31 days in 2 media comprised of hydatid fluid with ascitic fluid and hydatid fluid with "extrait globulaire." By this time, the scolices were vesicular and had increased from 25 to 30 times their original volume. Coutelen was also able to keep nonsterile vesicles from the liver of a pig for as long as 12 days, and believed that they could have been maintained much longer in vitro, had they been bacteriologically sterile.

In his material, Coutelen noted that the scolices evaginated within a few hours, with a gradual increase in size within 3 or 4 days. This increase in size took place in both evaginated and unevaginated scolices. By the 10th day, some scolices had increased to about 10 times their original volume, and during this time became vesicular. Although there was some thickening of the cuticle, he did not observe the development of lamination. In some cultures, on about the second day, minute, thin-walled vesicles were seen protruding from some scolices. It was also believed that original capsules containing scolices ruptured, everted, and then repaired the break, resulting in a vesicle with the scolices protruding from the external wall. Coutelen noted that about 1 scolex in 50 became vesicular.

Coutelen (1927b) later studied serial sections of material which had been kept for 12 days in a mixture of hydatid fluid and unheated bovine serum. In this culture were found all intermediate stages between normal scolices and those which had become vesicular. The observation was confirmed that capsules containing scolices rupture, evert, and then regain their vesicular form by repair of the rup- 
tured tissue. In this way, the thin layer of tissue formerly lining the vesicle covers the exterior surface. Coutelen made numerous observations on the development of vesicular scolices.

Dévé (1928) continued this work, being particularly concerned with the earlier failure to obtain actual lamination of the cuticle in vesicles derived from scolices. After several attempts, scolices were maintained for 43 days in a mixture of equal parts hydatid fluid and human ascitic fluid incubated at $37^{\circ} \mathrm{C}$. Minute vesicles deriving from vesicular scolices were found to have relatively thick, laminated cuticles. Dévé also reported the successful culture of scolices in collodion sacs implanted in the peritoneal cavity of rabbits. After 79 days, vesicles measuring up to $5 \mathrm{~mm}$ in diameter were found upon removal of the collodion sacs.

Aside from the fact that the species of cestode was different, the experiments of Dévé and Coutelen differed basically from those reported herein; they were concerned mainly with the changes taking place in scolices kept in vitro, while we attempted to produce vesicles from undifferentiated germinal tissue. In our first experiment, we noted an increase in the size of some of the scolices kept in vitro; these did not become vesicular, however, and soon degenerated. Since the scolices are the end product of larval development, it does not appear that they would provide a good source of new vesicles. However, new attempts to culture E. granulosus would seem desirable.

As outlined above, the larval E. multilocularis proliferates and produces scolices in vitro about as rapidly as in suitable intermediate hosts such as Microtus and Clethrionomys. Such scolices are presumably infective, although a sufficient number has not yet been obtained to make practicable an attempt to infect a canine final host. The fact that larval tissue removed from the culture tubes proliferates and produces scolices when introduced into the peritoneal cavity of a natural intermediate host is another indication that in vitro conditions, as outlined above, are not detrimental.

In the present experiments, larval proliferation diminished after a certain maximum size was attained. The larval masses probably become so large that the medium surrounding them soon becomes unfavorable. The use of larger containers with a rotating mechanism to provide some circulation of the medium would probably be beneficial.

The importance of the HeLa cells is not yet clear. However, they provided a substrate on which the larval tissue became attached, and permitted the aggregations of vesicles developing from a common origin to remain intact. The first evidence of growth of the cestode tissue was almost always noted in tubes containing HeLa cells. It is possible that these cells in some way stimulated the proliferation of this tissue. In the tubes lacking $\mathrm{HeLa}$ cells, the vesicles usually were separate and free in the medium, without much tendency to form large aggregations. However, the HeLa cells in older cultures often enclosed the vesicles so completely that their effect was considered detrimental.

Observations of larvae in vitro confirm the earlier conclusion that proliferation takes place through the exogenous budding of new vesicles (Rausch, 1954). The fluid medium allows a retention by the vesicles of a spherical shape, while in vivo they are no doubt affected by the resistance of the host tissue in which they occur. It is of interest that endogenous budding of vesicles was not observed in vitro, and 
there is so far no evidence that this takes place. Further study of the development of the larval E. multilocularis in vitro will facilitate an understanding of all aspects of its structure and growth.

It is believed that the availability of a larval cestode which is readily maintained in vitro may permit metabolic and other studies hitherto not practicable. It would also seem feasible to produce larval vesicles in quantities adequate for the production of antigens for use in the serological diagnosis of hydatid disease. This would have the advantage that the undesirable components of host tissue present in material obtained from infected animals would be lacking.

The larvae of E. multilocularis are capable of proliferating in a variety of mammals which are widely separated phylogenetically. In some host-species, the larvae develop normally and become infective; in others they are able to persist, but rarely produce infective scolices (Rausch and Schiller, 1956). This would seem to indicate an unusual capacity in this larval cestode to tolerate adverse conditions.

\section{Literature Cited}

Coutelen, F. 1927a Essai de culture in vitro de scolex et d'hydatides échinococciques (Echinococcus granulosus). Ann. Parasitol. hum. et comp. 5: 1-19.

$1927 \mathrm{~b}$ Sur l'évolution vésiculaire in vitro des scolex échinococciques. Ann. Parasitol. hum. et comp. 5: 239-242.

Dévé, F. 1926 Evolution vésiculaire du scolex échinococcique obtenue in vitro. La culture artificielle du kyste hydatique. Compt. rend. Soc. Biol. 94: 440-441.

1928 Scoliciculture hydatique en sac de collodion et in vitro. Compt. rend. Soc. Biol. 98: 1176-1177.

RaUsch, R. 1954 Studies on the helminth fauna of Alaska. XX. The histogenesis of the alveolar larva of Echinococcus species. J. Inf. Dis. 94: 178-186. AND Schiller, E. L. 1956 Studies on the helminth fauna of Alaska. XXV. The ecology, and public health significance of Echinococcus sibiricensis Rausch and Schiller, 1954, on St. Lawrence Island. Parasitology (In press). 